\title{
Correction to: Exploring the Psychometric Properties of the Empathy Quotient for Farsi Speakers
}

\author{
Stefanie A. Wind ${ }^{1,2} \cdot$ Parvaneh Yaghoubi Jami $^{1} \cdot$ Behzad Mansouri ${ }^{1}$
}

Published online: 25 August 2018

(C) Springer Science+Business Media, LLC, part of Springer Nature 2018

\section{Correction: Current Psychology \\ https://doi.org/10.1007/s12144-018-9938-z}

The original version of this article unfortunately contained a mistake in the author group section. The correct name of the second author is Parvaneh Yaghoubi Jami.

The original article has been corrected.

The online version of the original article can be found at https://doi.org/ 10.1007/s12144-018-9938-Z

Stefanie A. Wind

swind@ua.edu

1 The University of Alabama, Tuscaloosa, AL, USA

2 Educational Studies in Psychology, Research Methodology, \&

Counseling, The University of Alabama, Box 870231,

Tuscaloosa, AL 35487, USA 